Research Article

\title{
Mechanical Behavior of Cemented Sand Reinforced with Different Polymer Fibers
}

\author{
Xiangfeng Lv $\mathbb{D}^{1,2}$ Xiaohui Yang, ${ }^{3}$ Hongyuan Zhou, ${ }^{3}$ and Shuo Zhang ${ }^{3}$ \\ ${ }^{1}$ School of Civil and Resource Engineering, University of Science \& Technology Beijing, Beijing 100083, China \\ ${ }^{2}$ Beijing Key Laboratory of Urban Underground Space Engineering, University of Science \& Technology Beijing, \\ Beijing 100083, China \\ ${ }^{3}$ Geotechnical Engineering Research Center, Institute of Municipal Engineering, Beijing 100037, China
}

Correspondence should be addressed to Xiangfeng Lv; beijingmerilvxf@163.com

Received 11 March 2019; Accepted 16 May 2019; Published 12 June 2019

Academic Editor: Pietro Russo

Copyright ( 2019 Xiangfeng Lv et al. This is an open access article distributed under the Creative Commons Attribution License, which permits unrestricted use, distribution, and reproduction in any medium, provided the original work is properly cited.

\begin{abstract}
In this study, the specimens of cemented sand were prepared by reinforcing it separately with different contents $(0.5 \%, 1.0 \%, 1.5 \%$, and $2.0 \%$ ) of three different polymer fibers (polyamide, polyester, and polypropylene) prepared as filaments of different lengths (6, 9 , and $12 \mathrm{~mm}$ ). Then, these specimens were tested, and the improvement effects of the three fibers on the engineering-mechanical behavior of the cemented sand were analyzed and compared. The different microstructures and chemical compositions of the fiber-reinforced cemented sand specimens were investigated using electron microscopy and X-ray diffraction. Compression tests were performed to obtain the stress-strain curves of the specimens. Comparative analysis was performed on the variation patterns of the mechanical parameters (such as unconfined compressive strength and peak strain) of the specimens. Quantitative analysis was performed on the effect of fiber content and fiber filament length on the failure mode of the specimens. It was shown that the inclusion of fibers led to a change from brittle failure to ductile failure. The macro- and microexperimental results revealed that polypropylene fiber had the best improvement effect on the mechanical behavior of the cemented sand, followed by polyester fiber and polyamide fiber. In particular, the cemented sand specimen reinforced with $1.5 \%$ polypropylene fiber prepared as $9 \mathrm{~mm}$ length filaments had a brittleness index of 0.0578 , exhibited ductile failure (in contrast to the brittle failure of the nonreinforced cemented sand), and yielded the highest unconfined compressive strength and shear strength among the specimens.
\end{abstract}

\section{Introduction}

Fiber-reinforced cemented sands have been widely studied in recent years. Studies have shown that different chemical fibers have different improvement effects on sands [1-5]. Khorami et al. [6] attempted to optimize the production of fiber-cement board (FCB) using polypropylene and acrylic fibers and found that compared to conventional FCBs, FCBs improved with the two fibers exhibited better compressive, shear, and flexural strengths and toughness. Consoli et al. [7-11] added the fiber to the sand and tested the parameters of cyclic shear response and tensile/compressive strength ratio after soil sand improvement. Fu et al. [12] carried out a comparative study of the performance of completely decomposed granite specimens reinforced separately with polypropylene and rubber fibers using nuclear magnetic resonance. Orasutthikul et al. [13] compared the mechanical behaviors of mortars reinforced separately with short filaments of recycled polyamide, poly(ethylene terephthalate), and polyvinyl alcohol. Liu and Pourrahimian [14] studied the effect of polyamide, glass, and steel fibers on the cracking behavior of expansive shotcrete mixtures and attempted to establish the correlation between parameters such as splitting tensile strength, volume change, density, and water absorption. Schabowicz et al. [15] presented an original methodology for identifying the degree of degradation of fiber-cement boards caused by high temperature with the acoustic emission method. Jiang et al. [16] using plant leaves as ecofriendly heat-insulating building materials, and five poplar leaf modification methods were employed to improve 
the compatibility between leaf fibers and cement-based materials in composites. Some scholars [17-19] have conducted some comparative tests on the reinforcing properties of the polyvinyl alcohol fiber to cement materials. There are few reports on the different improvement effects of different polymer fibers, particularly the micromorphology of critical factors, the effect of chemical composition, and the mechanism underlying the change from the brittle failure of nonreinforced sands to the ductile failure of fiber-reinforced sands.

In this study, cemented sand was reinforced separately with three different polymer fibers obtained from waste textile products-polyamide, polyester, and polypropylene fibers-at different contents and different filament lengths. The structures and bonding strengths of the fiber-reinforced cemented sand specimens were tested and analyzed using electron microscopy and X-ray diffraction (XRD). Then, unconfined compression tests were performed to compare the mechanical parameters (such as unconfined compressive strength and peak strain) of the specimens. The mechanism underlying the effect of the fibers on the failure mode (brittle or ductile) of the cemented sand was investigated by analyzing the variations in the stiffness coefficients and brittleness indexes of the specimens. This study will provide theoretical inputs for the selection of polymer fibers for the reinforcement of cemented sands and will be of reference value for future studies on the microdynamics and mechanical failure modes of fiber-reinforced composite materials.

\section{Experimental Materials and Methods}

\subsection{Experimental Materials}

2.1.1. Fibers. All three fibers used for testing were obtained from waste textile products and prepared as filaments of equal length using a fiber cutter. Then, the fiber filaments were tested to determine their tensile strengths and moduli of elasticity according to ASTM C150 [20] and ASTM C 109 [21]. Table 1 presents the basic physical properties of the three fiber filaments.

2.1.2. Silica Sand. The silica sand selected for the test was river sand, which is commonly used in projects. According to the IS 383 standard [22] and the IS 1542-1992 standard $[23,24]$, river sand was sieved to obtain well-graded silica sand with a fineness index in the range of 40-45. The physical properties of silica sand are shown in Table 2 . Figure 1 presents the grain size distribution curve of the sand.

2.2. Preparation of Specimens. The contents (by mass) of sand, cement, fiber, and water for a specimen were determined according to the methods proposed by Chen et al. [25] and Hamidi and Hooresfand [26]. In order to improve the hydrophilicity of the fiber and enhance the interfacial strength between the fiber and the cement-sand, three kinds of fibers were treated with potassium permanganate solution before preparing the sample of fiber-reinforced cement-sand soil. In potassium permanganate solution, the mass ratio of potassium permanganate to concentrated nitric acid is $1: 30$. The soaking time of fiber in solution is 1 minute. Cement and sand were evenly mixed in a mixer for five minutes. Then, water was added, and the blend was mixed for another three minutes. This was followed by the addition of fiber into the water-cement-sand mixture. To ensure that the fiber was evenly mixed with the mixture, the fiber was divided into five dosages, and each dosage was mixed for two minutes. The water-cement-sand-fiber mixture for each dosage was filled into a metal mold (radius of $38.8 \pm 0.2 \mathrm{~mm}$ and $80 \mathrm{~mm}$ in height) and impacted with a hammer for 20-25 hits [27]. The height of the final specimen was $80 \pm 0.2 \mathrm{~mm}$ [28]. The molded specimen was cured in a curing box for seven days (at a temperature of $25 \pm 2^{\circ} \mathrm{C}$ and humidity of greater than 90\%) [29]. The cured specimen was dried in a drying oven (at a temperature of $50^{\circ} \mathrm{C}$ ) until no change was observed in its mass. The dried specimen was ready for testing. Figure 2 shows the image of the specimen containing $0.5 \% 6 \mathrm{~mm}$ length polyester filaments.

\section{Experimental Results and Analysis}

3.1. Comparative Analysis of the Microbonding Structures of Fiber-Reinforced Cemented Sand Specimens. Figures 3(a)-3(c) show the images of the fiber-reinforced cemented sand specimens. The images were obtained using a $2.0 \mathrm{KX}$ scanning electron microscope. The images clearly show the different bonding structures of the specimens. The polyamide filaments (Figure 3(a)) appear as intervening bundles, with a large number of gel particles adhered on their surface and noticeable pores between them. This microstructure has a negative effect on the compressive strength and other engineering properties of the cemented sand matrix. In contrast, the polyester and polypropylene filaments are embedded or inserted into the matrix (Figures 3(b) and $3(c)$ ), with a noticeable interface effect that contributes to better bonding between the components of the matrix. In summary, polyester and polypropylene are better bonded with the cemented sand matrix compared to polyamide, as revealed by the micromorphologies of the specimens.

3.2. Comparative Analysis of the Microstructures and Chemical Compositions of Fiber-Reinforced Cemented Sand Specimens. The chemical compositions of the three different fibers were analyzed using XRD [30-32]. X-ray diffractometer was used to analyze the three fiber components, and the diffraction pattern was shown in Figure 4. As can be seen from Figure 4, the diffraction pattern is well matched with the standard card. It proves that the three fibers are polypropylene fiber, polyamide fiber, and polyester fiber [33]. In addition, three fibers all have obvious diffraction peaks, indicating that the sample has crystallinity. Among them, the diffraction peak height of the nylon fiber is low and the area is small, indicating that the number of crystals is smaller and the volume is larger. The diffraction peak height and area of the polyester fiber and polypropylene fiber are larger, 
TABLE 1: Basic physical properties of fiber filaments.

\begin{tabular}{lccccc}
\hline Fiber description & Relative density & $\begin{array}{c}\text { Diameter of the fiber } \\
\text { filament }(\mathrm{mm})\end{array}$ & $\begin{array}{c}\text { Mean water } \\
\text { absorption rate (\%) }\end{array}$ & Modulus of elasticity (GPa) & Tensile strength (MPa) \\
\hline Polyamide & 1.20 & $0.76-0.81$ & 7.2 & 2.4 & 593 \\
Polyester & 1.31 & $0.73-0.71$ & 15.2 & 2248 & 356 \\
Polypropylene & 0.98 & 0.042 & 0.0 & 3.81 & 364 \\
\hline
\end{tabular}

TABle 2: Physical properties of silica sand.

\begin{tabular}{ccccccc}
\hline$C_{\mathrm{u}}$ & $C_{\mathrm{c}}$ & $e$ & $\gamma_{\text {d. } \max }\left(\mathrm{kN} / \mathrm{m}^{3}\right)$ & $\gamma_{\mathrm{d} \cdot \min }\left(\mathrm{kN} / \mathrm{m}^{3}\right)$ & $G_{\mathrm{s}}$ & $w(\%)$ \\
\hline 2.13 & 1.3 & 0.82 & 1.81 & 1.62 & 2.65 & 10.9 \\
\hline
\end{tabular}

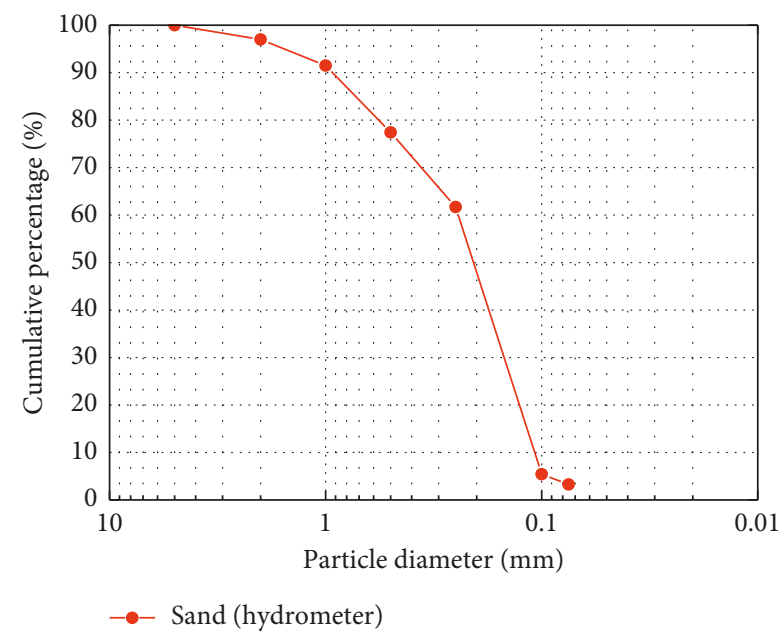

FIgURE 1: Grain size distribution curve of silica sand.

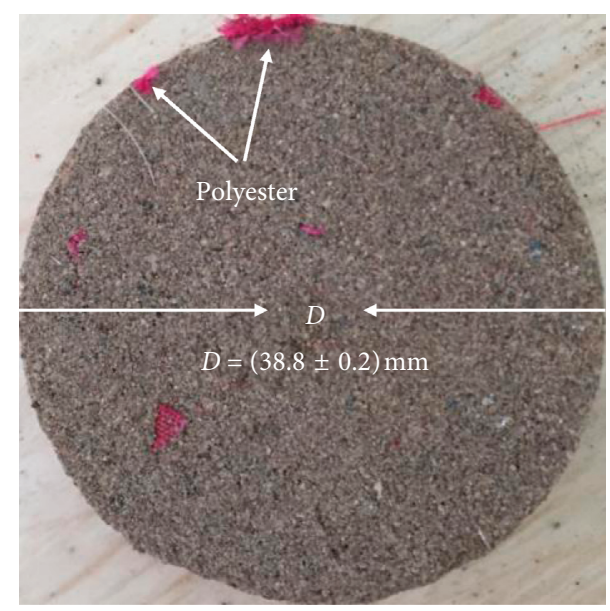

Figure 2: Dimensions of specimen.

indicating that the number of crystals is large and the crystal volume is small. It can be seen from the fluctuation of the diffraction curve that the noise of the polypropylene fiber is larger, indicating that the degree of crystallization is larger. In summary, the polypropylene fiber is a better option for reinforcing the cemented sand compared to polyester and polyamide fibers in terms of chemical composition.

\subsection{Comparative Micromechanical Analysis of Fiber- Reinforced Cemented Sand Specimens}

3.3.1. Micromorphology at Failure. Figures 5(a)-5(c) show the micromorphologies of the fiber-reinforced cemented sand specimens subjected to uniaxial compression (at a loading rate of $0.8 \mathrm{~mm} / \mathrm{min}$ ) using a strain-controlled automatic uniaxial compression tester. In Figure 5, the dotted line represents the cracks distributed on the surface of the damaged sample. Comparative analysis shows that a specimen reinforced with $9 \mathrm{~mm}$ length fiber filaments shows better properties than a specimen reinforced with the same content of $6 \mathrm{~mm}$ length fiber filaments. Only the micromorphologies of the specimens reinforced with $9 \mathrm{~mm}$ length fiber filaments are presented here owing to space limitation. For the same filament length, an increase in the fiber content results in a gradual change in the micromorphology of the specimens at failure. More specifically, specimens with lower fiber contents exhibit vertical isolated cracks, whereas specimens with higher fiber contents exhibit oblique treeleaf-shaped conjugated cracks or shear racks. This indicates that as the fiber content increases, the failure mode gradually changes from brittle failure at lower fiber contents to ductile failure at high fiber contents. Specimens with a fiber content of $1.5 \%$ exhibit the most noticeable characteristics of ductile failure. However, specimens with a higher fiber content of $2.0 \%$ exhibit irregular morphologies at failure characterized by irregular fork-shaped cracks. This indicates that a further increase in the fiber content results in decreased compressive strength and ductility. This can be explained by the following mechanism: extremely high fiber content results in the overlapping of fiber filaments and decrease in the interface effect. The specimens reinforced by polypropylene fiber exhibit more regular morphologies at failure compared to the other specimens. Particularly, the specimen reinforced with $1.5 \% 9 \mathrm{~mm}$ length polypropylene fiber filaments exhibits the most typical ductile failure among the specimens.

Figure 6 shows the unconfined compressive strengths of the fiber-reinforced cemented sand specimens. At a filament length of $6 \mathrm{~mm}$, higher fiber content results in higher compressive strength, as shown in Figure 6(a). In particular, an increase in the content of the polypropylene fiber results in a larger increase in unconfined compressive strength compared to the cases of polyester and polyamide. The specimen containing $1.5 \%$ polypropylene fiber exhibits the highest unconfined compressive strength of $1034.5 \mathrm{kPa}$. At a fiber filament length of $9 \mathrm{~mm}$, as the fiber content increases, the unconfined compressive strengths of the specimens reinforced with polyester and polyamide fibers first increase and peaks at 1296.4 and $911.3 \mathrm{kPa}$, respectively, at a fiber content of $0.5 \%$, and then decrease. The specimens 


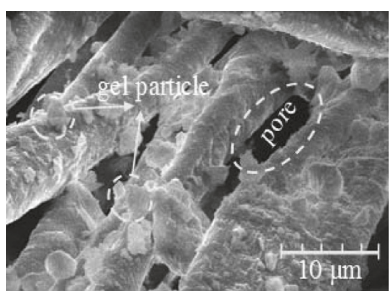

(a)

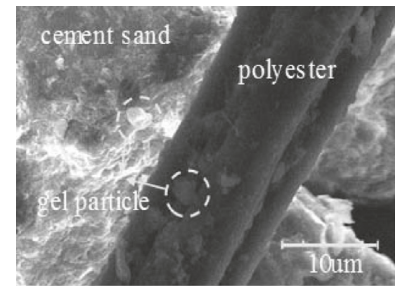

(b)

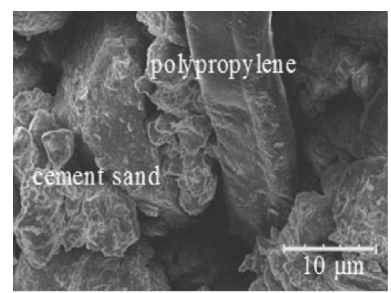

(c)

FIGURE 3: Micromorphologies of fiber-reinforced cemented sand specimens: (a) polyamide; (b) polyester; (c) polypropylene.

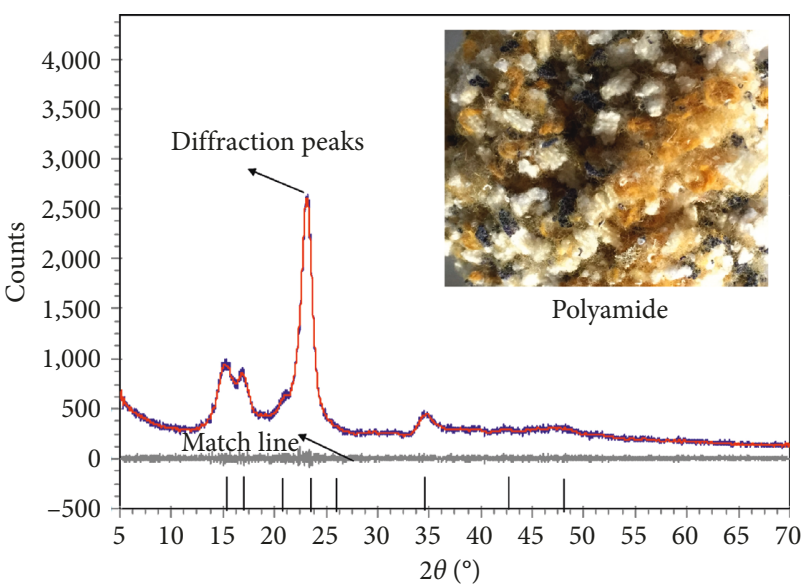

(a)

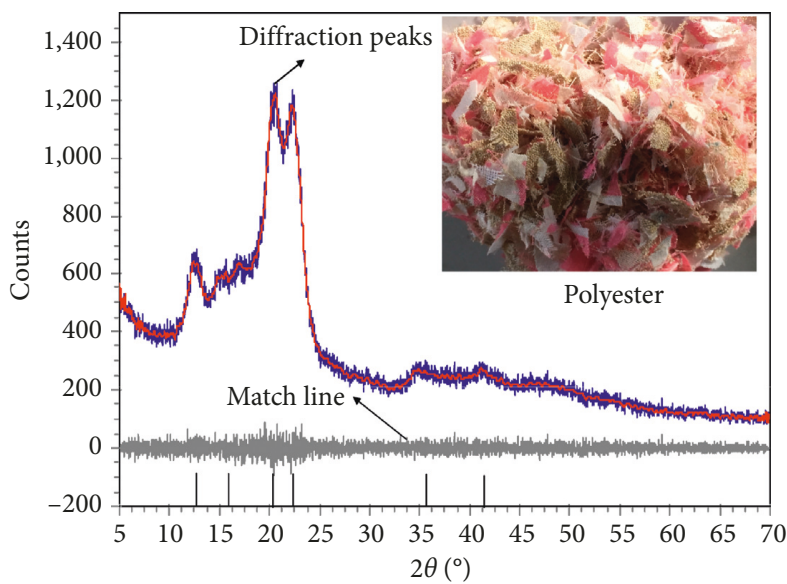

(b)

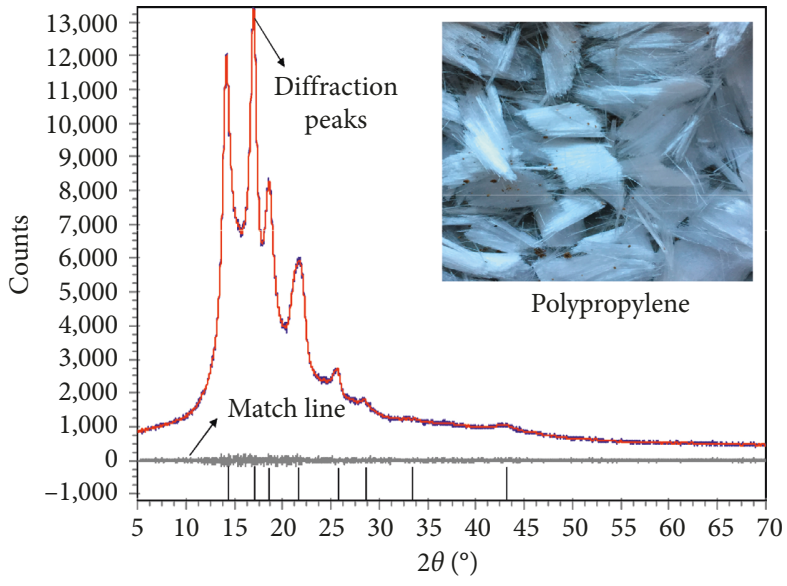

(c)

Figure 4: X-ray diffraction spectra of different fibers: (a) polyamide; (b) polyester; (c) polypropylene.

reinforced with the polypropylene fiber exhibit a similar trend of unconfirmed compressive strength as the fiber content increases. In particular, unconfined compressive strength increases considerably when the polypropylene fiber content is increased from $1.0 \%$ to $1.5 \%$, with the peak unconfined compressive strength of $1467.6 \mathrm{kPa}$ occurring at a fiber content of $1.5 \%$. As shown by the unconfined compressive strength curves for the fiber-reinforced specimens, the peak values of unconfined compressive strength decrease noticeably as the fiber content is increased from
$1.5 \%$ to $2.0 \%$. This indicates that extremely high fiber content has a negative impact on the properties of the fiberreinforced cemented sand. The comparative analysis of the effect of the filament length on the peak unconfined compressive strength of the specimens shows that the peak values of the specimens reinforced with $9 \mathrm{~mm}$ length fiber filaments are generally higher than those of the specimens reinforced with $6 \mathrm{~mm}$ length and $12 \mathrm{~mm}$ length fiber filaments. This further demonstrates that the optimum filament length for reinforcing the cemented sand is $9 \mathrm{~mm}$. 


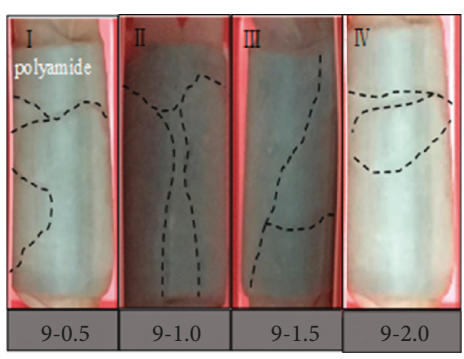

(a)

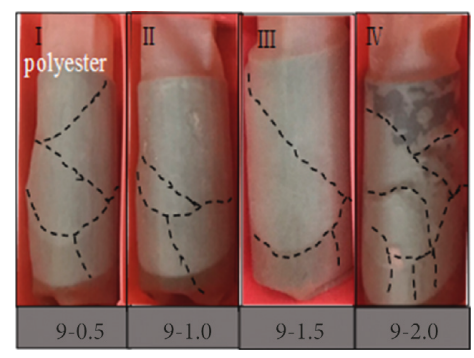

(b)

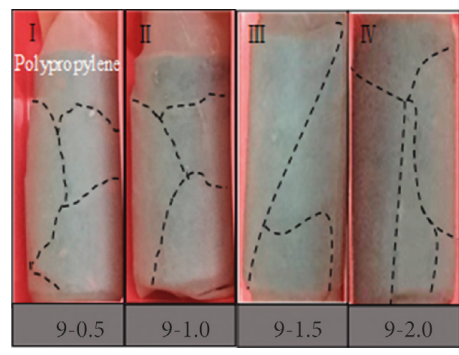

(c)

Figure 5: Micromorphologies at failure of specimens subjected to uniaxial compression: (a) $9 \mathrm{~mm}$ polyamide; (b) $9 \mathrm{~mm}$ polyester; (c) $9 \mathrm{~mm}$ polypropylene.

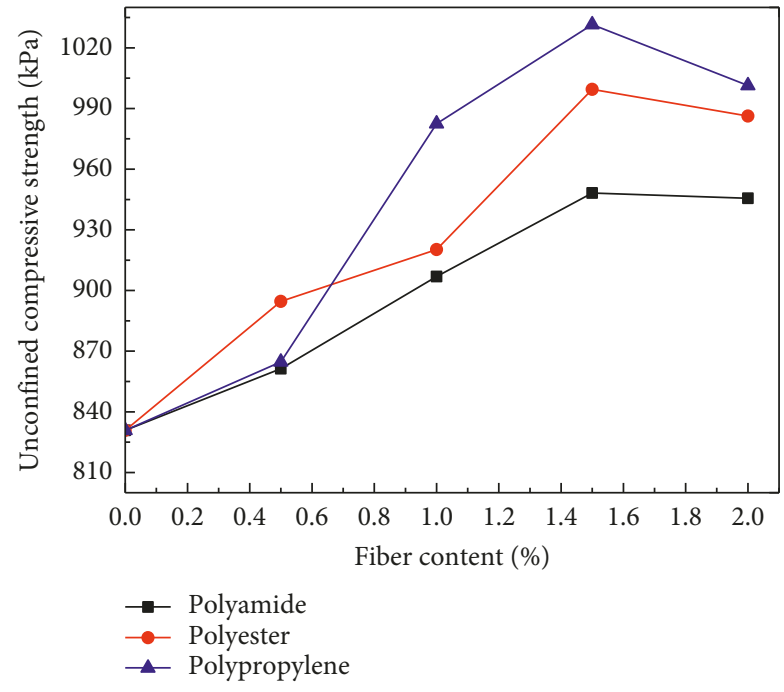

(a)

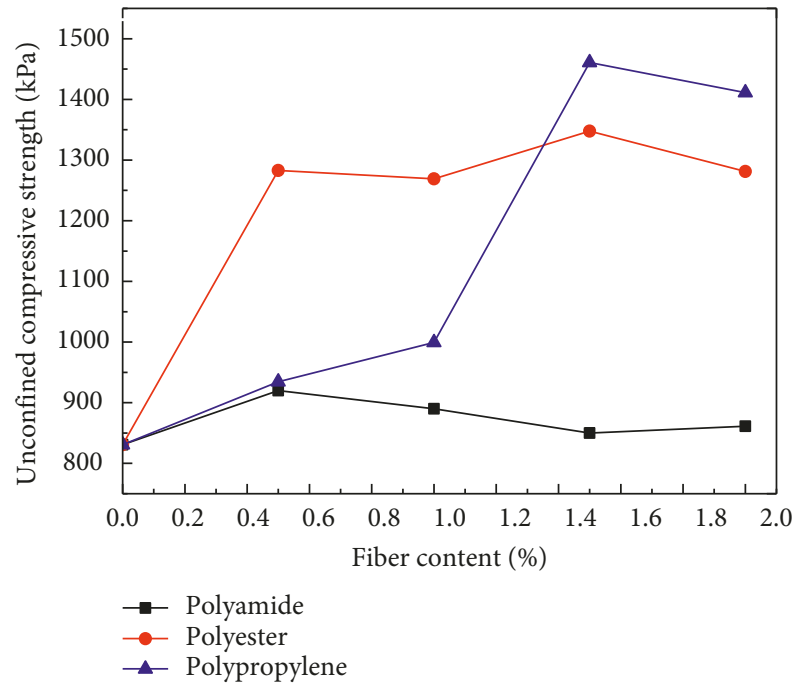

(b)

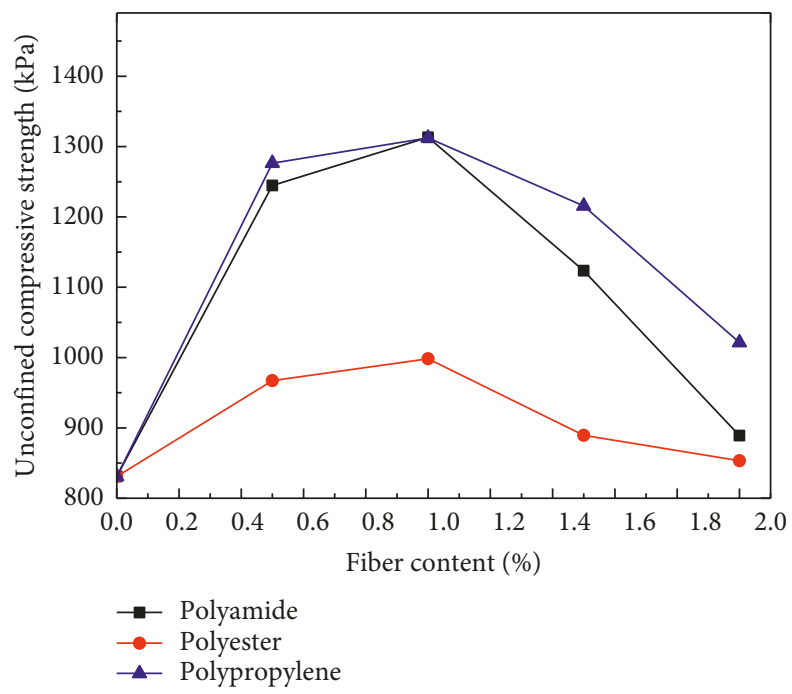

(c)

Figure 6: Curves of peak values of unconfined compressive strength: (a) $6 \mathrm{~mm}$; (b) $9 \mathrm{~mm}$; (c) $12 \mathrm{~mm}$.

3.3.2. Brittleness Index Variation Patterns. The analysis of the brittleness of fiber-reinforced sand helps understand the possibility of the brittle failure of a sand matrix when subjected to a certain load. This facilitates the prevention of engineering accidents. The brittleness indexes of the fiberreinforced cemented sand specimens subjected to different confining pressures $(100,300$, and $500 \mathrm{kPa})$ were computed [34]. The computed brittleness indexes are presented in 
TABLE 3: Brittleness indexes of fiber-reinforced cemented sand specimens.

\begin{tabular}{|c|c|c|c|c|c|c|c|c|c|}
\hline \multirow{3}{*}{ Fiber type } & \multicolumn{9}{|c|}{ Brittleness index $\left(I_{\mathrm{B}}\right)$} \\
\hline & \multicolumn{3}{|c|}{ Fiber length $=6 \mathrm{~mm}$} & \multicolumn{3}{|c|}{ Fiber length $=9 \mathrm{~mm}$} & \multicolumn{3}{|c|}{ Fiber length $=12 \mathrm{~mm}$} \\
\hline & $100 \mathrm{kPa}$ & $300 \mathrm{kPa}$ & $500 \mathrm{kPa}$ & $100 \mathrm{kPa}$ & $300 \mathrm{kPa}$ & $500 \mathrm{kPa}$ & $100 \mathrm{kPa}$ & $300 \mathrm{kPa}$ & $500 \mathrm{kPa}$ \\
\hline \multirow{4}{*}{ Polyamide } & 1.0496 & 0.4268 & 0.3136 & 0.5441 & 0.2564 & 0.2564 & 0.8683 & 0.5873 & 0.2816 \\
\hline & 1.1450 & 0.3631 & 0.2558 & 0.7383 & 0.1589 & 0.1589 & 1.1450 & 0.4653 & 0.1655 \\
\hline & 0.7677 & 0.2244 & 0.2243 & 0.7195 & 0.1086 & 0.1086 & 0.6387 & 0.6712 & 0.1621 \\
\hline & 0.7132 & 0.23 .1 & 0.2461 & 0.6814 & 0.1927 & 0.2874 & 0.6211 & 0.8357 & 0.2031 \\
\hline \multirow{4}{*}{ Polyester } & 0.5911 & 0.3114 & 0.1278 & 0.9532 & 0.4786 & 0.2322 & 0.8123 & 0.5739 & 0.3267 \\
\hline & 0.8567 & 0.3392 & 0.1773 & 0.8912 & 0.3630 & 0.2127 & 0.7367 & 0.6783 & 0.2369 \\
\hline & 0.7360 & 0.5415 & 0.2663 & 0.7616 & 0.4441 & 0.1885 & 0.7210 & 0.8764 & 0.2646 \\
\hline & 1.2360 & 0.8433 & 0.3114 & 0.9214 & 0.5791 & 0.2613 & 0.7163 & 1.0238 & 0.3816 \\
\hline \multirow{4}{*}{ Polypropylene } & 0.5406 & 0.3242 & 0.1470 & 0.6914 & 0.2255 & 0.5180 & 0.7236 & 0.5262 & 0.2470 \\
\hline & 0.3337 & 0.137 & 0.1198 & 0.3655 & 0.1604 & 0.2255 & 0.8346 & 0.6791 & 0.1521 \\
\hline & 0.4058 & 0.1918 & 0.1012 & 0.2332 & 0.0578 & 0.1604 & 0.8896 & 0.8459 & 0.2134 \\
\hline & 0.6771 & 0.3 .58 & 0.2131 & 0.5546 & 0.2174 & 0.0078 & 1.2486 & 0.7143 & 0.3129 \\
\hline
\end{tabular}

Table 3. The experimental data reveal that, for the same fiber content and fiber filament length, the brittleness index increases with confining pressure. Figure 7 compares the brittleness indexes of the fiber-reinforced cemented sand specimens subjected to a confining pressure of $500 \mathrm{kPa}$. The brittleness index is computed using the following equation:

$$
I_{\mathrm{B}}=\frac{q_{\mathrm{max}}}{q_{\mathrm{res}}}-1,
$$

where $I_{\mathrm{B}}$ is the brittleness index, $q_{\max }$ is the unconfined compressive strength, and $d$ is the residual strength.

Figures $7(\mathrm{a})-7$ (c) show that, at the same confining pressure, the brittleness index decreases with an increase in the fiber content. This indicates that the inclusion of the three chemical fibers allows for the transition from the brittle failure to the ductile failure of the cemented sand. The brittleness index reflects the degree of postpeak stress loss, with a larger index indicating larger stress loss. The inclusion of fibers results in a smaller brittleness index, indicating smaller stress loss. This is consistent with the stress-strain curves, thereby confirming that the inclusion of the three chemical fibers contributes to an improvement in the postpeak mechanical properties of the cemented sand. The above variation patterns of the brittleness index are consistent with the finding of Mashhadban et al. [35]. For the same fiber content, the brittleness indexes of the specimens reinforced with polypropylene fiber are smaller than those of the specimens reinforced with polyester and polyamide fibers. Among the specimens, the specimen reinforced with $9 \mathrm{~mm}$ length polypropylene fiber filaments subjected to a confining pressure of $500 \mathrm{kPa}$ has the smallest brittleness index of 0.0578 . Furthermore, this specimen exhibits ductile failure. This quantitatively confirms that the polypropylene fiber is a better option for reinforcing the cemented sand.

3.3.3. Correlation between Strength Parameters. Figures 8 and 9 show the relationships between the unconfined compressive strength and residual strength and between the cohesion and residual cohesion, respectively, of the fiber-reinforced cemented sand specimens. Figures 8(a)- 8(d) show that there exists a linear correlation between the peak strength and residual strength of the fiber-reinforced cemented sand specimens. The correlation coefficients are larger than 0.75 for all specimens, and the overall correlation coefficient is 0.86 . Figures 9 and 10 show that there exists a nonlinear correlation between cohesion and residual cohesion and between the angle of internal friction and the residual angle of internal friction; the correlation coefficient is 0.75 in both cases. The correlation coefficient data demonstrate reliable correlations between strength parameters. These correlations are a major input for predicting the strength parameters of fiber-reinforced cemented sands and developing numerical models for the constitutive relation of fiber-reinforced cemented sands.

\section{Conclusions}

Cemented sand was reinforced separately with three different polymer fibers (polyamide, polyester, and polypropylene fibers) obtained from waste textile products. The microstructures, morphologies, and engineeringmechanical behaviors of the fiber-reinforced cemented sand specimens were analyzed and compared. Our findings are summarized below.

(1) All three recycled fibers improved the engineeringmechanical properties of the cemented sand, such as unconfined compressive strength, residual strength, peak strain, and residual strain. Polypropylene had the best improvement effect, followed by the polyester fiber and polyamide fiber.

(2) For polypropylene fiber-reinforced cemented sand, the optimum fiber content was $1.5 \%$ and the optimum fiber filament length was $9 \mathrm{~mm}$. With the optimum content and filament length, the polypropylene fiber improved the unconfined compressive strength, peak strain, and shear strength of the cemented sand by $62.3 \%, 21.8 \%$, and $224.7 \%$, respectively. 


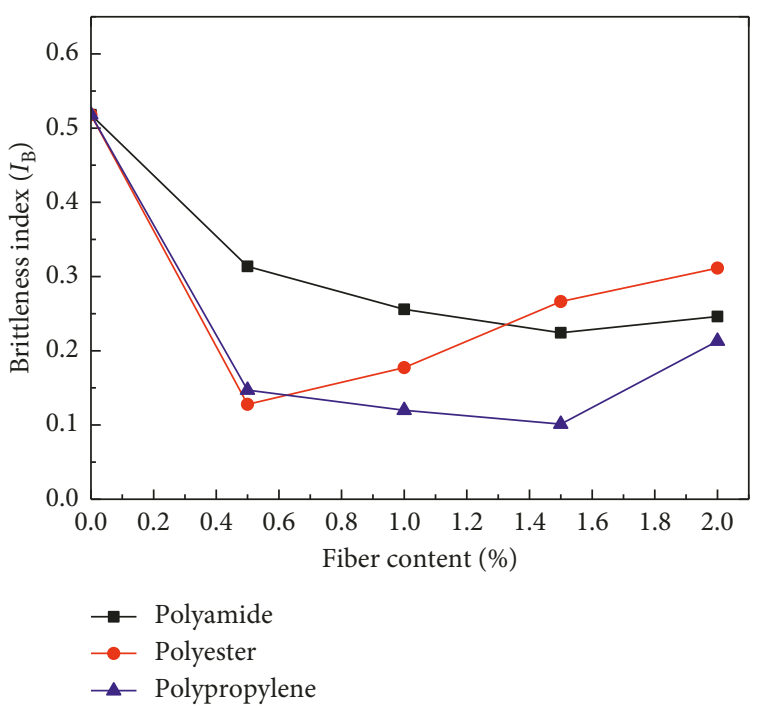

(a)

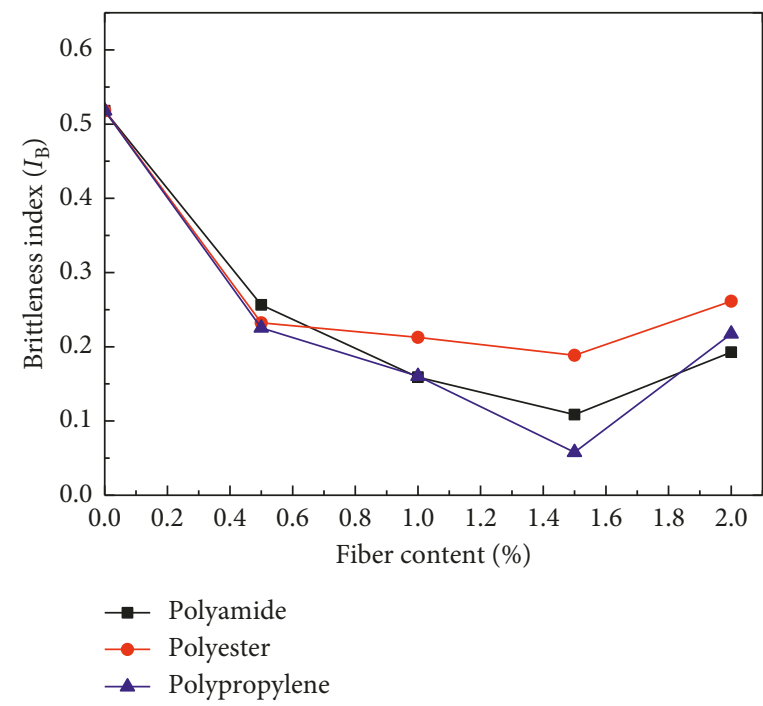

(b)

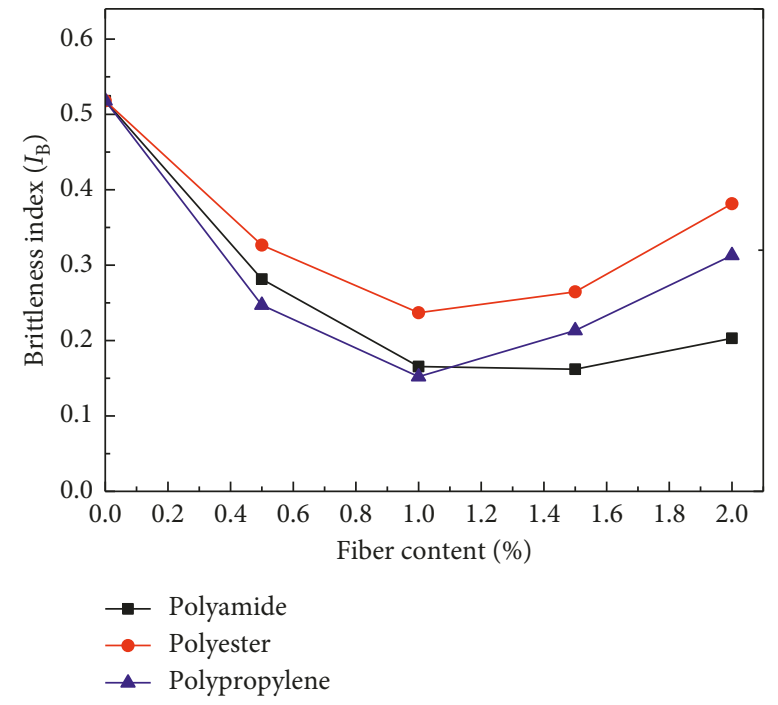

(c)

Figure 7: Brittleness index variation pattern: (a) $6 \mathrm{~mm}$; (b) $9 \mathrm{~mm}$; (c) $12 \mathrm{~mm}$.

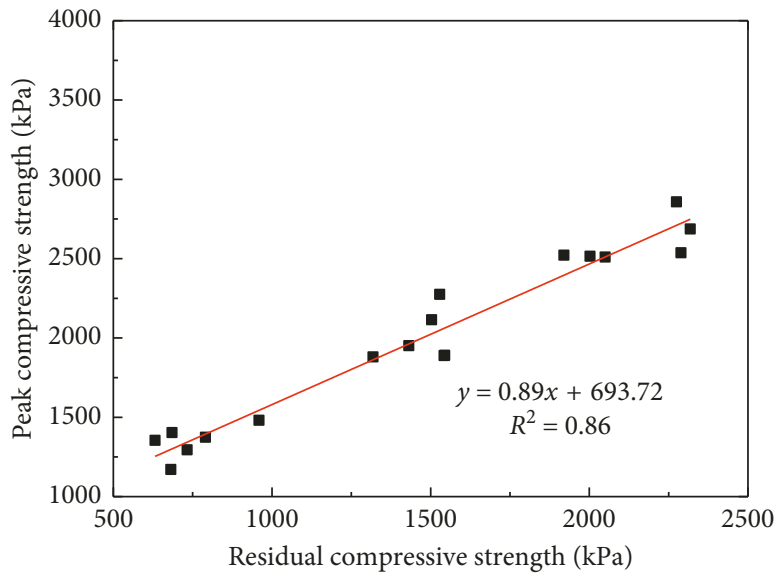

- Experimental data Fitting line

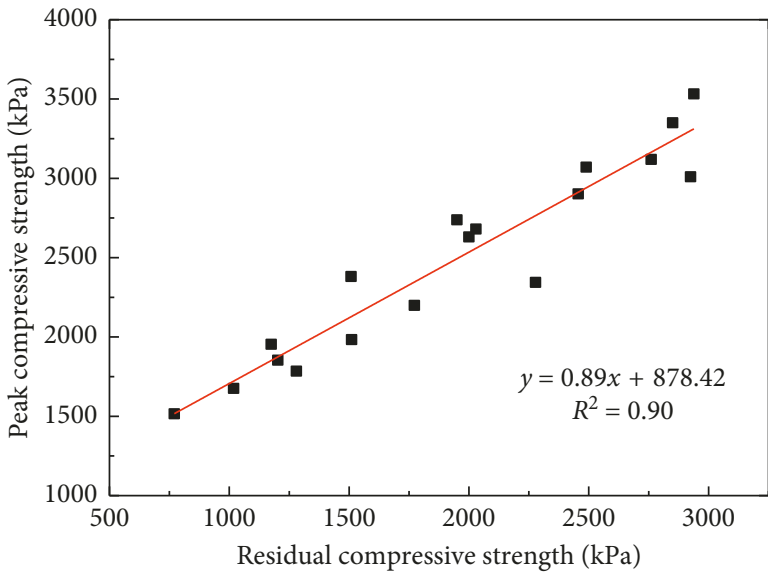

- Experimental data Fitting line

(a)

Figure 8: Continued. 


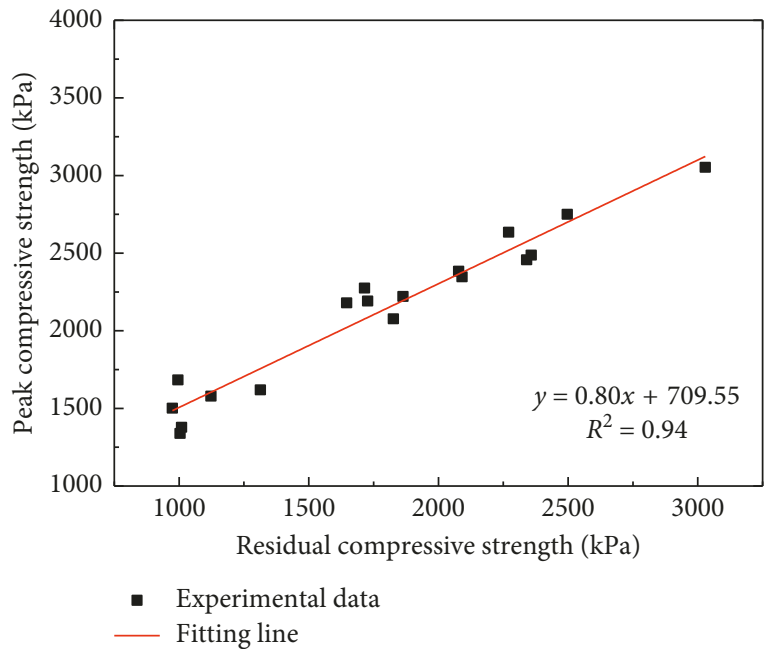

(c)

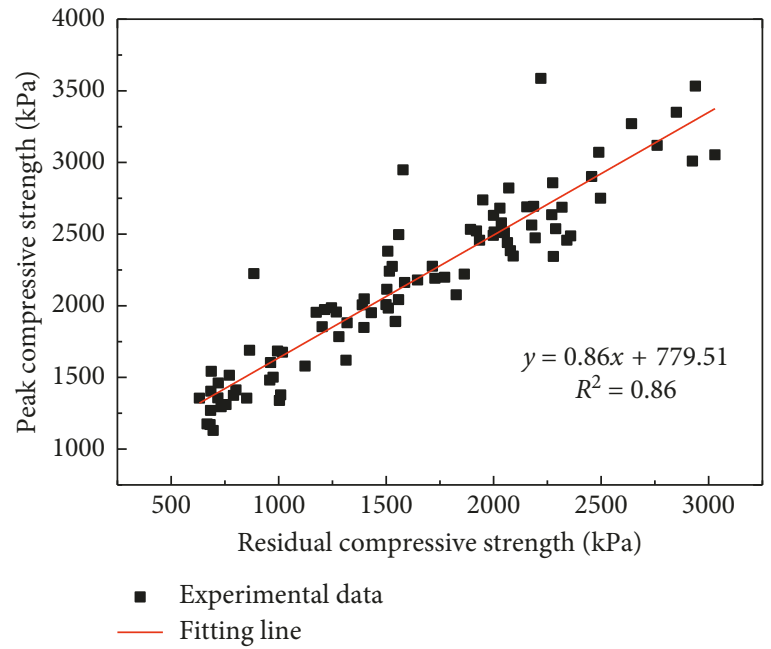

(d)

FIGURE 8: Correlation between peak strength and residual strength of fiber-reinforced cemented sand specimens: (a) polyamide fiberreinforced cemented sand; (b) polyester fiber-reinforced cemented sand; (c) polypropylene fiber-reinforced cemented sand; (d) fiberreinforced cemented sand (overall pattern).

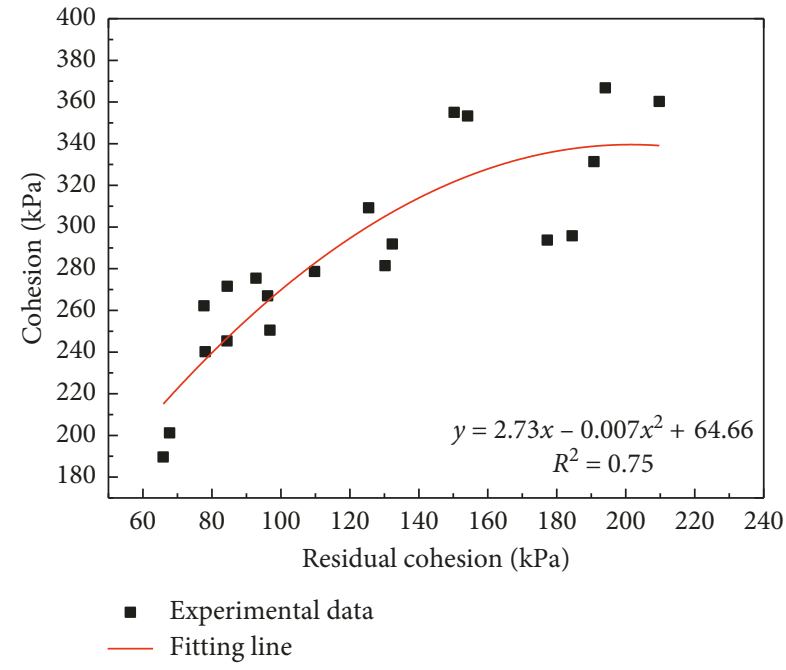

FIGURE 9: Correlation between the cohesion and residual cohesion of cemented sand specimens reinforced with different fibers.

(3) The nonreinforced cemented sand exhibited brittle failure, whereas the fiber-reinforced cemented sand exhibited ductile failure. The cemented sand specimens reinforced with lower fiber contents exhibited vertical cracks, whereas the specimens reinforced with higher fiber contents exhibited tree-leaf-shaped cracks. The inclusion of fiber filaments resulted in a lower brittleness index of the cemented sand. The optimum brittleness index achieved by the polypropylene fiber-reinforced cemented sand was 0.0578 .

(4) Fitting was performed for the cohesion, residual cohesion, angle of internal friction, and residual angle of internal friction of the fiber-reinforced cemented sand specimens. The fitted correlation

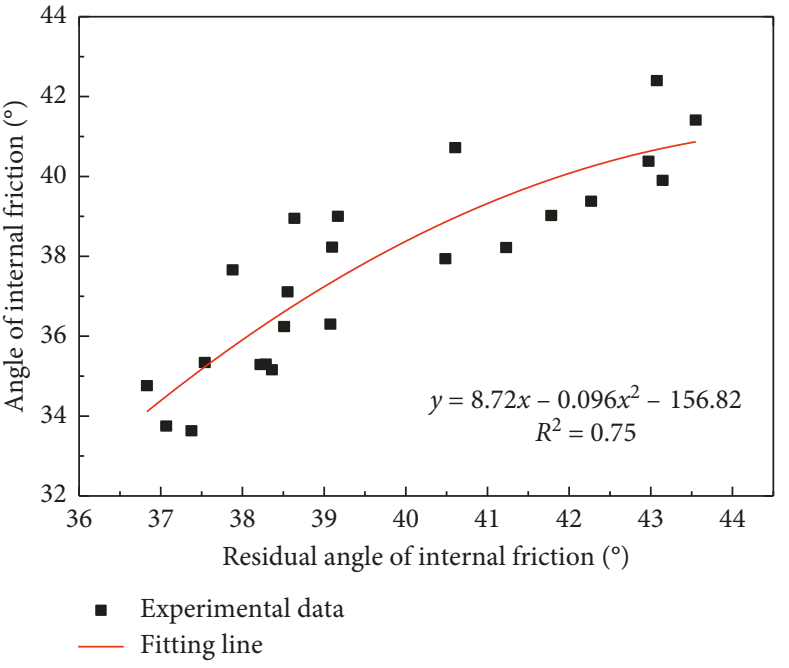

FIgURE 10: Correlation between the angle of internal friction and residual angle of internal friction of cemented sand specimens reinforced with different fibers.

coefficients for the cemented sand specimens reinforced with polyamide, polyester, and polypropylene fibers were $0.86,0.90$, and 0.94 , respectively, and the overall correlation coefficient was 0.86 .

\section{Data Availability}

The data used to support the findings of this study are available from the corresponding author upon request.

\section{Conflicts of Interest}

The authors declare that they have no conflicts of interest. 


\section{Acknowledgments}

This work was supported by National Natural Science Foundation of China (Project numbers 51504029 and 51774048), Beijing Talent Foundation (Project number 2017000021223ZK04), Beijing Nova Program (Project number Z161100004916083).

\section{References}

[1] T. Gonçalves, R. V. Silva, J. de Brito, J. M. Fernández, and A. R. Esquinas, "Hydration of reactive $\mathrm{MgO}$ as partial cement replacement and its influence on the macroperformance of cementitious mortars," Advances in Materials Science and Engineering, vol. 2019, Article ID 9271507, 12 pages, 2019.

[2] Q. Tang, P. Shi, Y. Zhang, W. Liu, and L. Chen, "Strength and deformation properties of fiber and cement reinforced heavy metal-contaminated synthetic soils," Advances in Materials Science and Engineering, vol. 2019, Article ID 5746315, 9 pages, 2019.

[3] S.-S. Park, "Effect of fiber reinforcement and distribution on unconfined compressive strength of fiber-reinforced cemented sand," Geotextiles and Geomembranes, vol. 27, no. 2, pp. 162-166, 2009.

[4] S. K. Saman and J. C. Asskar, "Triaxial behavior of fiberreinforced cemented sand," Journal of Adhesion Science and Technology, vol. 30, no. 6, pp. 579-593, 2016.

[5] C. Tang, B. Shi, W. Gao, F. Chen, and Y. Cai, "Strength and mechanical behavior of short polypropylene fiber reinforced and cement stabilized clayey soil," Geotextiles and Geomembranes, vol. 25, no. 3, pp. 194-202, 2007.

[6] M. Khorami, E. Ganjian, and A. Srivastav, "Feasibility study on production of fiber cement board using waste kraft pulp in corporation with polypropylene and acrylic fibers," Materials Today: Proceedings, vol. 3, no. 2, pp. 376-380, 2016.

[7] N. C. Consoli, M. A. Vendruscolo, and P. D. M. Prietto, "Behavior of plate load tests on soil layers improved with cement and fiber," Journal of Geotechnical and Geoenvironmental Engineering, vol. 129, no. 1, pp. 96-101, 2003.

[8] N. C. Consoli, M. A. Vendruscolo, A. Fonini, and F. D. Rosa, "Fiber reinforcement effects on sand considering a wide cementation range," Geotextiles and Geomembranes, vol. 27, no. 3, pp. 196-203, 2009.

[9] N. C. Consoli, R. R. de Moraes, and L. Festugato, "Parameters controlling tensile and compressive strength of fiberreinforced cemented soil," Journal of Materials in Civil Engineering, vol. 25, no. 10, pp. 1568-1573, 2013.

[10] L. Festugato, A. Fourie, and N. C. Consoli, "Cyclic shear response of fibre-reinforced cemented paste backfill," Géotechnique Letters, vol. 3, no. 1, pp. 5-12, 2013.

[11] L. Festugato, A. Peccin da Silva, A. Diambra, N. C. Consoli, and E. Ibraim, "Modelling tensile/compressive strength ratio of fibre reinforced cemented soils," Geotextiles and Geomembranes, vol. 46, no. 2, pp. 155-165, 2018.

[12] R. Fu, B. A. Baudet, B. N. Madhusudhan, and M. R. Coop, "A comparison of the performances of polypropylene and rubber fibers in completely decomposed granite," Geotextiles and Geomembranes, vol. 46, no. 1, pp. 22-28, 2018.

[13] S. Orasutthikul, D. Unno, and H. Yokota, "Effectiveness of recycled nylon fiber from waste fishing net with respect to fiber reinforced mortar," Construction and Building Materials, vol. 146, pp. 594-602, 2017.

[14] W. V. Liu and Y. Pourrahimian, "Effects of fibers on expansive shotcrete mixtures consisting of calcium sulfoaluminate cement, ordinary Portland cement, and calcium sulfate," Journal of Rock Mechanics and Geotechnical Engineering, vol. 10, no. 2, pp. 212-221, 2018.

[15] K. Schabowicz, T. Gorzelańczyk, and M. Szymków, "Identification of the degree of fibre-cement boards degradation under the influence of high temperature," Automation in Construction, vol. 101, pp. 190-198, 2019.

[16] D. Jiang, P. An, S. Cui et al., "Effect of leaf fiber modification methods on mechanical and heat-insulating properties of leaf fiber cement-based composite materials," Journal of Building Engineering, vol. 19, pp. 573-583, 2018.

[17] W. Zhang, X. Zou, F. Wei et al., "Grafting SiO2 nanoparticles on polyvinyl alcohol fibers to enhance the interfacial bonding strength with cement," Composites Part B: Engineering, vol. 162, pp. 500-507, 2019.

[18] J. Qiu, X. N. Lim, and E.-H. Yang, "Fatigue-induced in-situ strength deterioration of micro-polyvinyl alcohol (PVA) fiber in cement matrix," Cement and Concrete Composites, vol. 82, pp. 128-136, 2017.

[19] Y. Li, W. Li, D. Deng, K. Wang, and W. H. Duan, "Reinforcement effects of polyvinyl alcohol and polypropylene fibers on flexural behaviors of sulfoaluminate cement matrices," Cement and Concrete Composites, vol. 88, pp. 139-149, 2018.

[20] ASTM C150, Standard Specification for Portland Cement, Annual Book of ASTM Standards. ASTM, Philadelphia, PA, USA, 2007.

[21] ASTM C 109, Standard Test Method for Compressive Strength of Hydraulic Cement Mortar, ASTM International, West Conshohocken, PA, USA, 1999.

[22] IS 383-1970, Coarse and Fine Aggregates From Coarse and Fine Aggregates From Natural Sources for Concrete, Bureau of Indian Standards, New Delhi, India, 1997.

[23] IS 2116-1980, Specification for sand for masonry mortars, Bureau of Indian Standards, New Delhi, India, 1980.

[24] IS 1542-1992, Sand for Plaster-Specification, Bureau of Indian Standards, New Delhi, India, 1992.

[25] M. Chen, S.-L. Shen, A. Arulrajah, H.-N. Wu, D.-W. Hou, and Y.-S. Xu, "Laboratory evaluation on the effectiveness of polypropylene fibers on the strength of fiber reinforced and cement-stabilized Shanghai soft clay," Geotextiles and Geomembranes, vol. 43, no. 6, 2015.

[26] A. Hamidi and M. Hooresfand, "Effect of fiber reinforcement on triaxial shear behavior of cement treated sand," Geotextiles and Geomembranes, vol. 36, pp. 1-9, 2013.

[27] ASTM D 1632, Standard Practice for Making and Curing Soil-Cement Compression and Flexure Test Specimens in the Laboratory, ASTM International, West Conshohocken, PA, USA, 2007.

[28] ASTM D 1633, Standard Test Methods for Compression Strength of Molded Soil-Cement Cylinders, ASTM International, West Conshohocken, PA, USA, 2000.

[29] R. Kalpokaitè-Dičkuvienè, A. Baltušnikas, R. Levinskas, and J. Čèsnienè, "Incinerator residual ash-metakaolin blended cements: effect on cement hydration and properties," Construction and Building Materials, vol. 206, pp. 297-306, 2019.

[30] M. A. Ismail, H. A. Joer, W. H. Sim, and M. F. Randolph, "Effect of cement type on shear behavior of cemented calcareous soil," Journal of Geotechnical and Geoenvironmental Engineering, vol. 128, no. 6, pp. 520-529, 2002.

[31] S. K. Saxena and R. M. Lastrico, "Static properties of lightly cemented sand," Journal of the Geotechnical Engineering Division, vol. 104, no. GT12, pp. 1449-1464, 1978. 
[32] R. S. Ladd, "Preparing test specimens using under compaction," Geotechnical Testing Journal, ASTM, vol. 1, no. 1, pp. 16-23, 1978.

[33] C. Naber, S. Stegmeyer, D. Jansen, F. Goetz-Neunhoeffer, and J. Neubauer, "The PONKCS method applied for time resolved XRD quantification of supplementary cementitious material reactivity in hydrating mixtures with ordinary Portland cement," Construction and Building Materials, vol. 214, pp. 449-457, 2019.

[34] S. R. Kaniraj and V. G. Havanagi, "Behavior of cementstabilized fiber-reinforced fly ash-soil mixtures," Journal of Geotechnical and Geoenvironmental Engineering, vol. 127, no. 7, pp. $574-584,2001$

[35] H. Mashhadban, S. S. Kutanaei, and M. A. Sayarinejad, "Prediction and modeling of mechanical properties in fiber reinforced self-compacting concrete using particle swarm optimization algorithm and artificial neural network," Construction and Building Materials, vol. 119, pp. 277-287, 2016. 


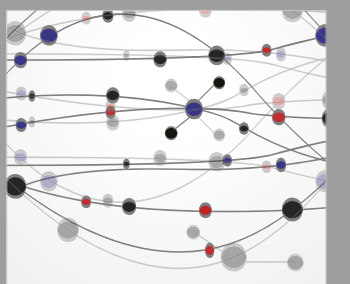

The Scientific World Journal
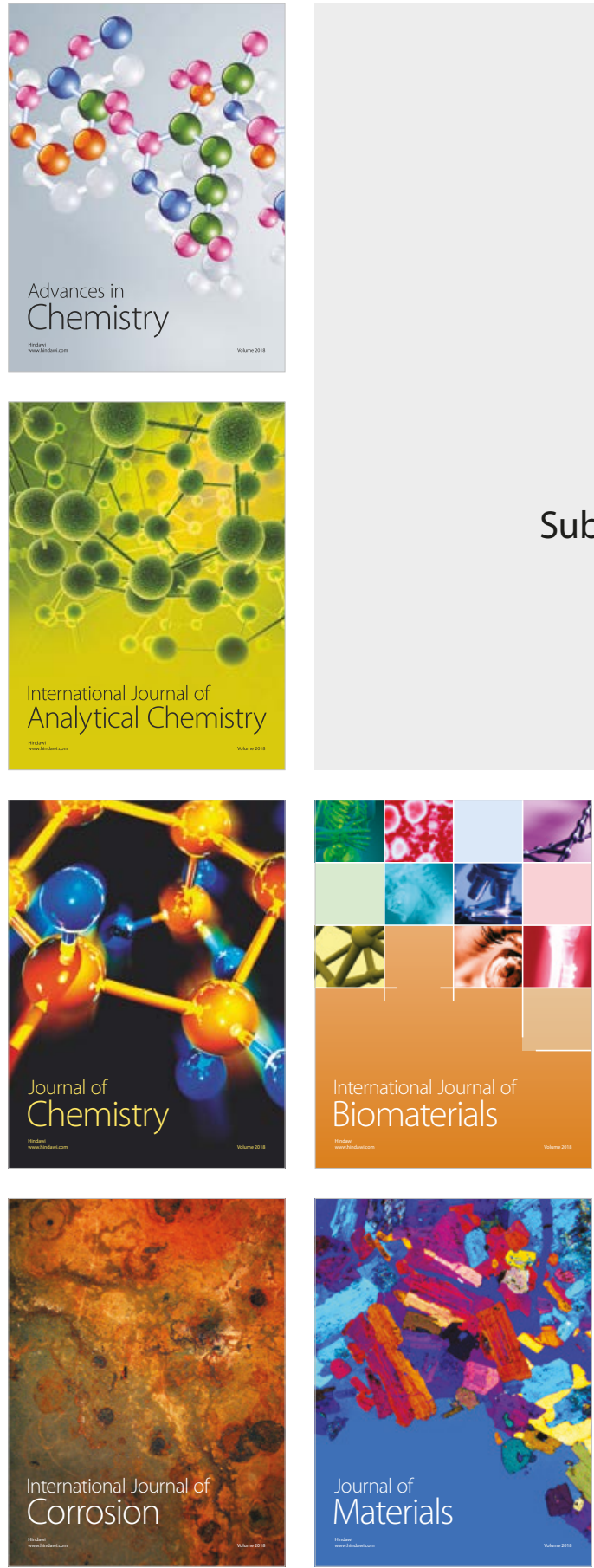

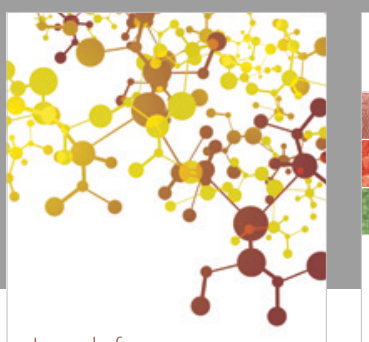

Journal of

Applied Chemistry
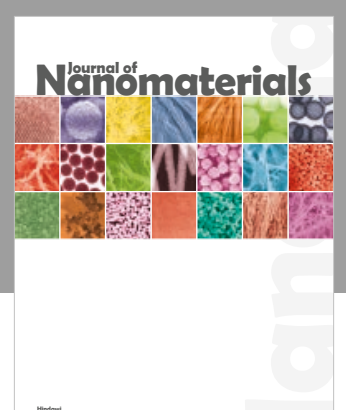

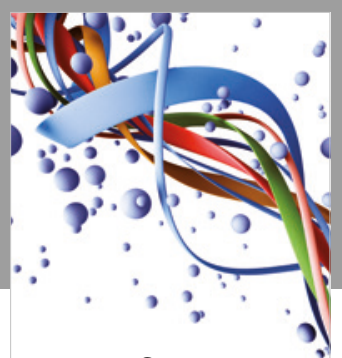

Scientifica

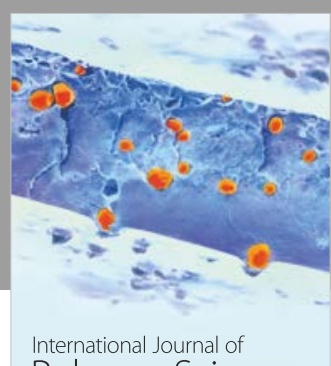

Polymer Science

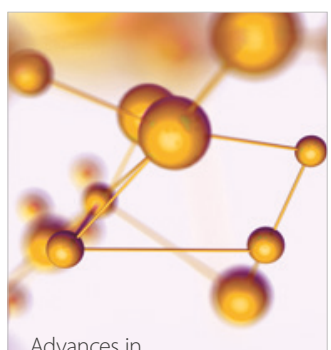

Physical Chemistry
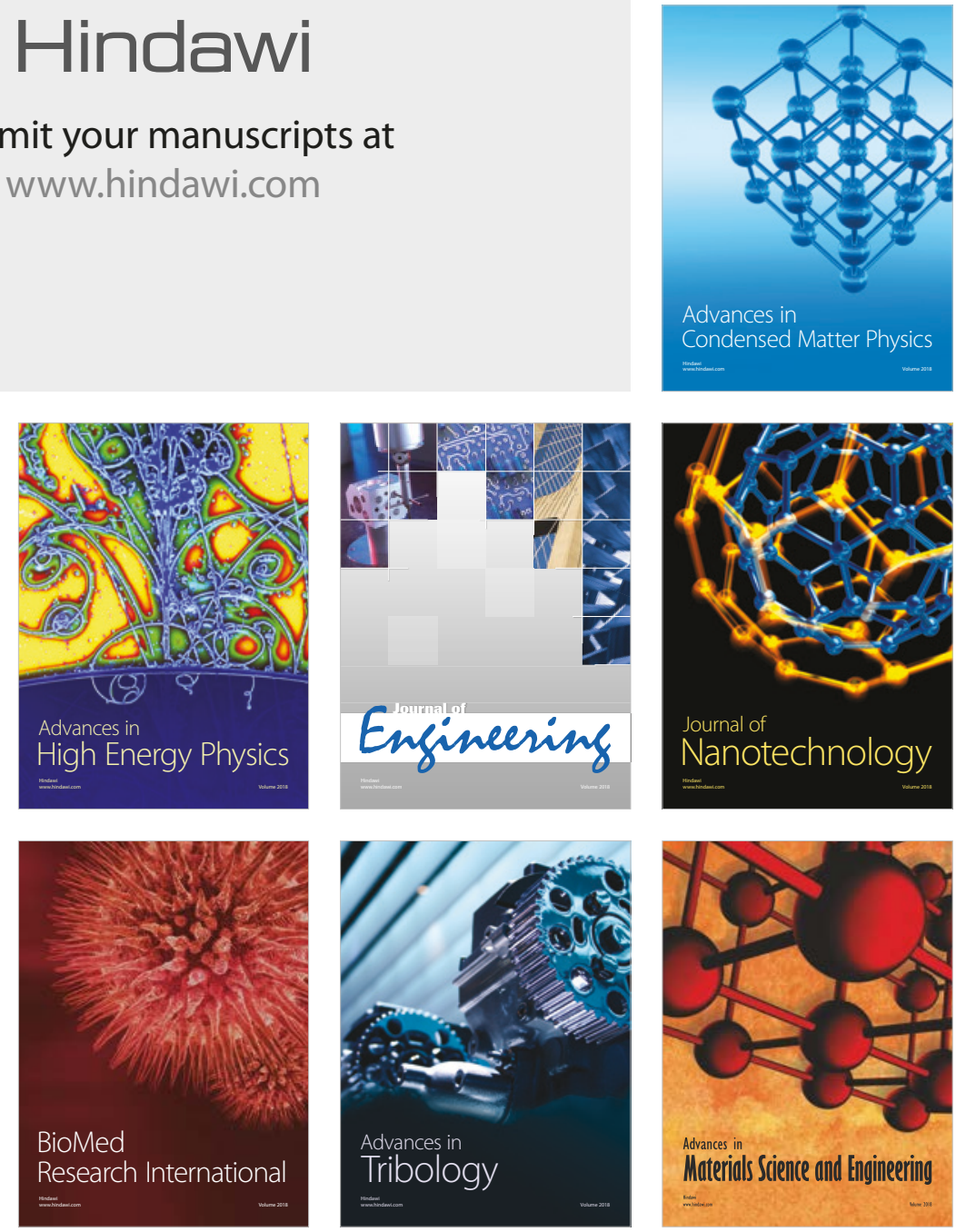